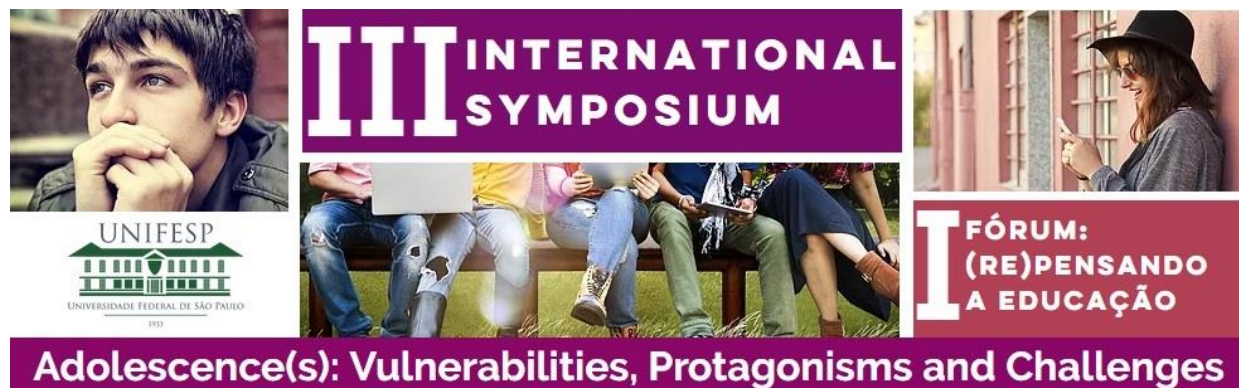

FUTURE BELVEDERE: WALK TOWARDS THE INSTITUTIONS POINTED OUT LIMITS AND POSSIBILITIES IN THE LIVES OF TEENS - THE ACADEMIC EXPERIENCE IN A PROJECT EXTENSION

\title{
FUTURO BELVEDERE: CAMINHAR EM DIREÇÃO AS INSTITUIÇÕES DE ENSINO APONTOU LIMITES E POSSIBILIDADES NA VIDA DE ADOLESCENTES - A VIVÊNCIA ACADÊMICA EM UM PROJETO DE EXTENSÃO
}

\author{
Jéssica Alice Nunes ${ }^{1}$; André Amorim Martins² \\ 1. Acadêmica do curso de Psicologia da Universidade do Estado de Minas Gerais (UEMG) \\ E-mail: jessicanunes3@ hotmail.com
}

2. Psicólogo, Mestre em Ciências (UFRJ), Orientador de TCC, Supervisor de estágio e Docente do curso de graduação em Psicologia (UEMG). Líder do Grupo de Pesquisa CNPq/UEMG Núcleo de Psicologia sobre Educação, Paz, Saúde, Subjetividade e Trabalho E-mail: andre.martins@uemg.br

*Projeto de Extensão desenvolvido com adolescentes do bairro Belvedere da cidade de Divinópolis-MG, pela Universidade do Estado de Minas Gerais (UEMG), financiado pelo Programa Institucional de Apoio à Extensão (PAEx)

\footnotetext{
Como citar:

NUNES, Jéssica Alice; MARTINS, André Amorim. Future belvedere: walk towards the institutions pointed out limits and possibilities in the lives of teens - the academic experience in a project extension. In:

INTERNATIONAL SYMPOSIUM ADOLESCENCE(S) \& FÓRUM (RE)PENSANDO A EDUCAÇÃO, 3 , 2017, São Paulo. Anais... São Paulo: Unifesp, 2017. p. 394-404.

DOI: http://dx.doi.org/10.22388/2525-5894.2017.32
}

\begin{abstract}
Resumo: O presente trabalho é resultado de um projeto de extensão desenvolvido com adolescentes na Unidade Básica de Saúde (UBS) do bairro Belvedere da cidade de Divinópolis- MG. O projeto ocorreu de Março a Dezembro de 2016, com a iniciativa de investigar diferentes aspectos da produção de subjetividade de adolescentes do bairro, com objetivo de entender suas relações com o meio em que vivem, em um processo de produção de um novo futuro e um despertar para as novas possibilidades de desenvolvimento junto a sociedade. Esses adolescentes desconheciam as oportunidades que lhes são oferecidas devido à falta de informação. Para haver efetividade nas ações, foi preciso conhecer estas oportunidades de acesso ao ensino de forma vivencial, para fazer valer o que lhes é de direito. Foram realizadas entrevistas, dinâmicas, exposição de filme, atividades lúdicas, palestras e visitas guiadas em instituições de ensino. Emergiram quatro categorias: a) Percepção das vivências anteriores às visitas as instituições; b) Percepções posteriores, despertando para maiores possibilidades; c) O empoderamento na ação participativa de cada um no processo de conquista de autonomia; d) Conscientização dos direitos sociais e civis no processo de mudanças sociais.

Palavra-chave: Adolescentes, serviços de saúde para adolescentes, desenvolvimento do adolescente.
\end{abstract}

Abstract: The present study is the result of an extension project developed with adolescents in the Basic Health
Unit (UBS) of the Belvedere neighborhood of the city of Divinópolis, MG. The project took place from April to
December 2016, with the initiative of investigating different aspects of the subjectivity production of adolescents
in the neighborhood, in order to understand their relationships with the environment in which they live, in a
process of producing a new future and a new possibilities for development within society. These adolescents
were unaware of the opportunities offered to them due to lack of information. To be effective in the actions, it 
was necessary to know these opportunities of access to teaching in an experiential way, to assert what is rightfully theirs. Interviews, dynamics, film exposure, play activities, lectures and guided visits were carried out in educational institutions. Four categories emerged: a) Perception of experiences prior to visits to institutions; b) Later perceptions, awakening to greater possibilities; c) Empowerment in the participative action of each one in the process of conquest of autonomy; d) Awareness of social and civil rights in the process of social change. Keywords: Adolescents, adolescent health services, adolescent development.

\section{INTRODUÇÃO}

As atividades no bairro Belvedere acontecem desde o ano de 2012, com atividades pactuadas com a gestão da Unidade Básica de Saúde. Dentre essas atividades estão: o grupo de mulheres, grupo de gestantes e puérperas, grupo de redução de danos ao tabagismo, acolhimento e atendimento a crianças, homens, e público em geral. O que se pode ver de contexto no bairro Belvedere II, através de observações, trabalhos, projetos e estágios desenvolvidos, é que o bairro passou por transformações ao longo dos últimos dez anos. Mas apesar das novas construções, o bairro apresenta alta vulnerabilidade para o público adolescente, perpassado pela precariedade de acesso aos serviços, marcado para ambos os sexos pela falta de oportunidades profissionais.

A dinâmica desenvolvida no projeto "Futuro Belvedere: Caminhar em Direção às Instituições Moveu com a Perspectiva de Futuro dos Adolescentes", ocorreu inicialmente pela busca ativa na Escola Municipal Hermínia Corgozinho onde se concentra um fluxo grande de adolescentes. Para convocar os adolescentes para o início das atividades foi realizado juntamente com a supervisora da Escola uma visita de sala em sala, convidando pessoalmente os adolescentes. Essa busca ativa possibilitou uma maior ligação da escola com o projeto, tendo retorno positivo do diretor, que incentivou a continuidade do projeto e das atividades com os adolescentes.

A escolha do bairro Belvedere para o desenvolvimento do projeto se deu a partir da necessidade de haver uma emancipação do público infanto-juvenil daquele bairro, na iniciativa de torná-los autores de suas próprias histórias. As estratégias de ação se deram a partir de propostas de visitação as instituições de ensino próximas ao bairro, através de palestras realizadas por outros profissionais, atividades esportivas, oficinas, filmes, discussões e demais atividades que pudessem despertar um empoderamento desses jovens.

Um aspecto importante a ser destacado é que esta população infanto-juvenil está entre importantes ferramentas públicas, como o Hospital Regional, a Universidade Federal de São João Del Rey- Campus Divinópolis (UFSJ), a nova estrutura da Prefeitura Municipal, a construção de três condomínios nas mediações do bairro, a aquisição da estadualização da Universidade do Estado de Minas Gerais (UEMG) e da nova Unidade Básica de Saúde no bairro, com estrutura apropriada para os cuidados de saúde, onde ofertam expressivamente de um crescimento quantitativo e qualitativo. No bairro e suas mediações já se tem construções 
antigas de grande importância, como o Centro Federal de Educação Tecnológica de Minas Gerais (CEFET), Centro de Formação Profissional Anielo Greco- SENAI, a rede de abastecimento de água da cidade COPASA, CEMEI, SEST/SENAT, duas escolas (sendo uma pública de ensino fundamental e outra estadual de ensino fundamental e médio) e dois clubes destinados a prática de esportes e lazer. O bairro Belvedere se caracteriza por ser um bairro periférico, limítrofe a BR-494, onde dá acesso a demais cidades da região.

A Unidade Básica de Saúde do bairro Belvedere está localizada na setorial Noroeste do município de Divinópolis (região mais populosa da cidade), que tem como referência a Unidade Especializada de Saúde do bairro São José. Vê-se da necessidade de cada vez mais ter revisões de ideias e valores que permeiam a vivência dos adolescentes e suas famílias.

O trabalho com adolescentes do Bairro Belvedere em Divinópolis vem sendo desenvolvido via projeto de extensão desde 2015, com apoio do Paex (Fapemig/UEMG). Em 2016 com o projeto: "Caminhar em direção às instituições moveu com a perspectiva de futuro dos adolescentes". As instituições que trabalhamos foram: UEMG, UFSJ, CEFET e SENAI, pois estão ao redor do Bairro. Participaram uma média de 20 adolescentes, com idades entre 11 e 16 anos. Após as visitas, foram feitas discussões a respeito do que foi vivenciado, fazendo um paralelo com suas experiências de vida, no qual os adolescentes traziam em seus discursos a vontade de abandonar os estudos para trabalharem como caixas de supermercado. Posteriormente, investigando suas perspectivas de vida, despertaram para uma preocupação quanto à progressão acadêmica e carreira profissional. Com isso, passaram a ter expectativas diante das possibilidades apresentadas. Sabemos que é preciso conhecer para fazer valer o que é de direito e identificamos que esses adolescentes desconheciam as possibilidades. $\mathrm{O}$ empoderamento dos adolescentes implicou em uma ação participativa de cada um, agindo de forma coletiva e participando de debates que visaram à conscientização dos direitos sociais e civis, agindo por mudanças sociais e ambientais atuais e futuras, em um processo de conquista de autonomia.

Nos ambientes apresentados ao grupo de adolescentes, ambientes a princípio públicos, foram observados e vivenciados aspectos paradoxais que aproximam e distanciam os sujeitos que ali vivem, transitam e convivem. Alguns dos princípios básicos e gerais não dependem somente dos jovens, mas de esforços de agentes já inseridos nos aparelhos públicos, no papel de aproximação dos jovens no sistema.

O termo Futuro Belvedere remete a um conjunto de fatos relacionados a um tempo que há de vir. Nota-se que todo adolescente precisa de oportunidades para expressar-se e desenvolver; precisam conhecer as ferramentas públicas e ter habilidades para realizar seus 
sonhos. Este é um período de conquista de sua autonomia e o futuro para eles, muitas vezes se coloca como uma interrogação.

A limitação dos projetos de vida para adolescentes vitimiza particularmente os grupos mais frágeis, numa crescente estrutura de desigualdade e injustiças, resultando em permanentes mecanismos de violência, podendo potencializar quadros críticos reproduzidos no Bairro. Crianças e adolescentes tem direitos legalmente assegurados e a violação destes por parte de responsáveis acarreta modificações no empenho futuro de cada um destes.

Grupos na adolescência desempenham função importante nessa fase do desenvolvimento humano. Esse período traz uma possibilidade de inserção social, para além do grupo familiar, onde estes têm oportunidade de partilhar ideias e sentimentos enquanto vivenciam um processo de mudança. Ainda tendo a possibilidade de interação com outros adolescentes compreendendo diferenças e semelhanças entre eles.

As atividades realizadas no bairro ao longo dos anos, possibilitaram identificar um contexto de vida precário, um bairro perpassado por escassez de acesso a espaços que deveriam ser destinados ao público do bairro, porém algumas instituições trazem o discurso de inacessibilidade, negligenciando acesso e gerando nos adolescentes impotência e reprodução de um discurso limitado de outras possibilidades. Tal situação pede que se consolidem projetos de vida para adolescentes, transcendendo informações que possam despertar nesses adolescentes a possibilidade de se inserirem nas instituições acadêmicas, em cursos técnicos, buscando uma melhor qualificação, lutando contra a perpetuação de escassez do Bairro. Observa-se que não é somente a limitação de projetos de vida no bairro que faz com que se perpetue o discurso escasso do Bairro, há muitas outras variáveis que impedem que adolescentes e jovens tenham projetos de vida. Dessa forma, fez-se necessário efetivar intervenções de extensão nos âmbitos em que esses adolescentes se inserem, observando atentamente o contexto de vida desses adolescentes para não haver generalizações e equívocos, que acabam correndo o risco de banalizar processos complexos.

A tomada de consciência e a conscientização da responsabilidade que cada um tem sobre a atual situação existencial, faz com que os adolescentes questionem e confrontem-se diante da mesma, é um dos papeis desenvolvidos pelo atual projeto de extensão. No presente texto, objetiva-se descrever em suma as atividades desenvolvidas no bairro Belvedere, no período de março a dezembro de 2016, com o grupo de adolescentes.

\section{DE QUAIS ADOLESCENTES FALAMOS?}

Amparada por estudos e revisões da literatura realizados a respeito das relações dos adolescentes em sociedade, ambientes diversos e instituições, observa-se que a adolescência é 
um período fértil do desenvolvimento humano para o estabelecimento de metas em relação ao futuro. Na Revisão de Literatura realizada por Zanon e Freitas (2016) encontram-se autores como Almeida e Cunha (2003), Piaget (1964/2007), Bremm e Bisol (2008), Damon (2009), que destacam a importância de elaborar projetos de futuro na adolescência, construindo referenciais sobre si e o mundo. Mas para que tudo isso ocorra, é preciso que conheçam suas possibilidades, seus direitos, deveres e que compreendam a necessidade de se trabalhar as questões de tempo, contexto e cultura.

A Organização Mundial de Saúde define adolescência como a fase do desenvolvimento compreendida entre os 10 e os 19 anos, critério adotado, no Brasil, pelo Ministério da Saúde e pelo Instituto Brasileiro de Geografia e Estatística (IBGE).

$\mathrm{Na}$ literatura vemos que falar sobre poder é muito frequente. Barus Michel (2004) diz que há relações de poder, onde existem posições diferentes e existem partes que tiram proveito, enquanto outras sofrem. Também encontramos referência ao desconhecimento, que não se trata de uma simples obscuridade, nasce na alienação dos atores sociais no ato que participam, usam os que não sabem, e esta pode se tornar generalizada. Na ausência de verdade definitiva, o sentido se constrói. O desconhecimento social causa sentimento de usurpação, amordaçando e mascarando a verdade. (BARUS-MICHEL, 2004).

Os adolescentes que residem no bairro Belvedere são desinformados a respeito de suas condições de cidadãos, desrespeitados de seus direitos e violentados por não fazerem parte de alguns contextos que são de direito deles acessarem. Nisso, nasce à necessidade de trabalhos, onde debates e autorreflexões críticas, sejam efetivos e possibilite uma visão maior das possibilidades ofertadas, no qual todos possam participar efetivamente do processo de construção criativa de algo em benefício à população.

O projeto "Futuro Belvedere" contou com a participação de adolescentes, a maioria participativa, havendo alguns casos que os impedissem de estarem presentes nos encontros. Dentre alguns dos casos, tivemos participante (P1) que preferiu abandonar o projeto ao longo de seu desenvolvimento, declarando preferir dormir depois do almoço. Também tivemos o caso dos três irmãos (P2) que deixaram de participar, pois foram ameaçados de morte, por gangues do próprio bairro, tendo então que sair às pressas de casa, mudando para outro bairro. Outro participante (P3) foi agredido no local onde eram realizados os encontros no término das atividades, fazendo com que gerasse certo desinteresse em continuar chegando a participar apenas esporadicamente. Outra participante (P4), foi impedida de continuar aos encontros, após uma discussão dos adolescentes do grupo com a mãe de (P4) na rua, a partir da discussão a mãe a proibiu de continuar participando dos encontros. Segundo a mãe de (P4), os adolescentes perturbavam os moradores do bairro com bagunças e barulhos. 
A violência é presente no contexto dos adolescentes, vemos com o autor, LÉVY (2001), que há várias formas de praticar a violência, seja ela no individual ou coletivo: boatos, absenteísmo, roubos, violências físicas ou psicológicas, oposições, pichações, depredação de patrimônios públicos e privados, comportamentos desviantes, a ponto de serem colocados como traços pessoais ligados à história individual, ou ao contexto social, mas como indicadores de ocultação social. Não é fácil determinar o grau de intensidade com base no qual um ato será ou não qualificado como violento. Trata-se sempre de uma questão de interpretação, relativa à cultura, às pessoas, ao contexto. $\mathrm{O}$ autor apropria a questão da violência buscando tematizar e explicar através de um contexto de práticas culturais, onde sua interpretação se dá através de uma sociedade marcada pelo autoritarismo e pela exclusão social.

A grande produção que fazemos é disparar algumas possibilidades de empoderamento na vida desses adolescentes, na possibilidade de fugir desse ciclo escasso de oportunidades que o próprio "Bairro" impõe. O trabalho que realizamos com esses adolescentes tem a proposta de ofertar possibilidades, além das que eles conhecem, para que eles possam escolher o caminho a percorrer, se tornando protagonistas de suas histórias. Agora não se tem apenas as opções de serviço braçal, ou funções operacionais como inicialmente eles discursavam (trabalhar como caixa de supermercado), a partir do desenvolvimento do "Futuro Belvedere", tem-se múltiplas opções a partir das vivencias, esses adolescentes têm opções de estudo, dentre outras oportunidades possíveis.

O objetivo principal desse trabalho é compreender as percepções dos adolescentes sobre a possibilidade de produção de um novo futuro, despertando os mesmos para um desenvolvimento junto a sociedade, com ações participativas de cada um no processo de conquista de autonomia e conscientização dos direitos sociais e civis no processo de mudanças sociais.

\section{METODOLOGIA}

Trata-se de um trabalho de extensão, com encontros semanais, realizados em um espaço ofertado pela Unidade Básica de Saúde do Bairro Belvedere II, na cidade de Divinópolis-MG, com discussões e visitas que buscam compreender e direcionar os adolescentes para uma reflexão sobre suas perspectivas de futuro. Os encontros são compostos por uma média de vinte adolescentes, com idades entre 11 e 16 anos, mediadas por uma graduanda curso de psicologia da UEMG/Divinópolis. Tem carga horária de 20 horas semanais com temas focados em trabalhar o protagonismo desses adolescentes no bairro em 
que residem, um bairro com possibilidades além das que são de conhecimento desses adolescentes.

Foram desenvolvidas várias temáticas ao longo do desenvolvimento do projeto, diferente em seus aspectos, mas focais com relação ao resultado final, que é a produção de subjetividade de cada indivíduo, valorizando seu modo de vida, assim facilitando o diálogo em grupo, proporcionando uma reflexão das propostas de um futuro com outras possibilidades. A disparada de possibilidades na vida dos adolescentes aumentou a visão sobre a capacidade social de ação. Abaixo, a produção dos encontros descritos sucintamente.

\section{OS ENCONTROS}

Foram totalizados uma média de quarenta encontros durante o período de março a dezembro de 2016, os mesmos, que moveram com as perspectivas dos adolescentes. Nos encontros iniciais, para que houvesse identificação dos adolescentes, foram realizadas apresentações de ambas as partes (facilitadora e grupo). Como identificação citaram nomes, idade, em qual localidade do bairro moravam, escola onde estudam e como ficaram sabendo do projeto. A maioria dos adolescentes veio da Escola Municipal do bairro, no qual foi feita a busca ativa desses adolescentes. O grupo se apresenta por um grupo aberto ao público infantojuvenil, por isso foi orientado que houvesse um convite dos participantes a demais conhecidos. Durante os encontros foram propostas diversas dinâmicas e oficinas.

Dentre as dinâmicas foram propostas aquelas que pudessem ser avaliado o trabalho em equipe, como eles estavam dispostos a fazerem o exercício e seguir as orientações. Em outra dinâmica foi estimulado que os adolescentes expusessem seus pensamentos, sentimentos e emoções. Tudo em uma proposta de abranger maior conhecimento dos adolescentes. Após distinguir o perfil do grupo, foi vista a necessidade de um melhor reconhecimento dos espaços públicos que mediavam o bairro, a partir dessa necessidade programamos primeiramente a visitação dos espaços institucionais de ensino, dentre eles a Universidade Federal de São João Del Rey- UFSJ Divinópolis, Centro Federal de Educação Tecnológica de Minas Gerais- CEFET Divinópolis, SENAI-FIEMG. A logística para a realização das visitas aconteceu da forma que para as instituições mais próximas, o percurso foi realizado a pé, o que proporcionou um momento para discutir durante o trajeto, sobre perspectivas, projetos e expectativas. Para os caminhos mais distantes foi disponibilizado por um funcionário da Unidade Básica de Saúde uma van para transportá-los.

As instituições reproduzem as violências sociais aqueles que não se submetem ao código escrito ou não escrito de "boa conduta" são ignorados de seus valores, deveres e direitos. Diante de um cenário onde muitas portas são fechadas e de oportunidades que 
parecem inalcançáveis, tentamos facilitar com uma experiência nova para o grupo Futuro Belvedere. O conhecimento adquirido e as experiências nas vivências dos adolescentes a partir das visitações foi o destaque no desenvolvimento do projeto. Tivemos recepções de diversas formas: visita guiada com práticas, palestra montada exclusivamente para a visita dos adolescentes, mostrando a preparação e o cuidado que tiveram em receber nosso grupo, apresentação do campus, e visitas sem maiores apresentações e sem abertura para exploração. Algumas instituições abriram as portas e mostraram a possibilidade de pertencer aquele espaço, já outras deixaram claras a insatisfação e o incomodo de tê-los ali naquele espaço. A forma como cada instituição nos recebeu disparou reflexões diferenciadas, foi nítida a preparação de alguns e despreparo de outros em receber os adolescentes do grupo Futuro Belvedere. Cada recepção nos mostrou o quanto os adolescentes podiam se sentir próximos ou afastados daqueles espaços. Nos discursos dos orientadores que nos receberam ficou evidenciado de forma clara o incentivo aos adolescentes em fazerem parte da instituição, sendo esta de possível inserção dos mesmos e em outros discursos a oposição em tê-los como membros participantes da instituição, em um processo de postergação.

Após as visitações, foi distribuído aos adolescentes questionários abertos, no qual foram perguntadas sobre as atividades realizadas. No questionário aberto, buscamos saber sobre as perspectivas anteriores e posteriores das visitas, também sobre as perspectivas anteriores a inserção no grupo Futuro Belvedere.

Contamos durante os encontros com a participação de outros profissionais, como a participação da Residente de Enfermagem da Universidade Federal de São João Del Rey e funcionária da Unidade Básica de Saúde do bairro Belvedere, no qual foi abordado o tema Sexualidade. Dentro do tema foi apresentado: Doenças Sexualmente Transmissíveis- DSTS, o meio de transmissão, tratamento, as formas de identificação, cuidados, uso de camisinha feminina e masculina (demonstrando cada passo na colocação do preservativo), prevenção, métodos contraceptivos. Falou-se da necessidade de acompanhamento médico e chamou atenção para eles participem da UBS, marcando preventivo para as meninas que se propuseram a fazer. Chamando a atenção para os cuidados de saúde da população, chegando os adolescentes para mais próximo desses cuidados.

Em seguimento com a temática do encontro com a residente de enfermagem, focamos em nos apropriar da oportunidade de desenvolver uma atividade voltada para a reflexão sobre os cuidados de saúde que foram aprendidos pelos adolescentes com a orientação da enfermeira, a relação que aqueles adolescentes tinha com a UBS e o que mais eles propusessem a fazer em forma de bricolagem (atividade que tem forma livre de se fazer e com qualquer material). Divididos em grupos, com os instrumentos que eles mesmos tinham 
levado, iniciaram a atividade de bricolagem, onde fluíram muitas ideias como: caminhões de saúde, maquetes de UBS, a necessidade de cuidados expostas em cartazes, tudo com muita colaboração e criatividade.

Contamos também com a participação do instrutor de capoeira e profissional de Educação Física, que acredita que uma roda de capoeira é um espaço propício a conhecer pessoas, fazer amizades, divertir e relaxar. A atividade ocorreu no espaço externo da Unidade Básica de Saúde, que chamou atenção de todos, e ganhou uma proporção ativa na junção de dois projetos de extensão da UEMG. Foi levado mais um conhecimento aos adolescentes nesse dia, uma possibilidade de participarem do grupo, "Capoeira: das senzalas à universidade" que visa ofertar capoeira à comunidade em geral. A intenção é agregar à capoeira a rotina desses com intenção de se apropriarem de mais um espaço próximo deles e gratuito.

No propósito de levar mais um conhecimento, apresentamos o Programa Jovem Aprendiz ao grupo de adolescentes. Que é um programa para aprimoramento constante que almeja desenvolvimento e crescimento profissional, dentro de uma área de atuação especifica, um programa que valoriza também a educação. A atividade fez com que também voltássemos nossa atenção para uma Oficina de Currículos, onde os adolescentes foram orientados passo a passo na confecção de currículos. Todos os interessados tiveram a oportunidade de produzir seus próprios currículos no notebook disponibilizado para a produção da atividade.

No encontro final houve uma discussão entre facilitadora e grupo, para que pudessem refletir diante do que foi vivenciado, produzido durante os encontros, a importância da continuidade do projeto, e o desenvolvimento de outros modelos na região.

A subjetividade é parte histórica da trajetória do ser humano, onde ele é produto e produtor de sua história, dentro de suas possibilidades e limitações dentro de todo o contexto que é inserido. Como atores sociais e reprodutores irreflexivos das situações, os trabalhos desenvolvidos devem possibilitar autorreflexão crítica, mudanças efetivas, conscientização da dimensão do espaço amplo em que podemos trabalhar, refletindo sempre da multiplicidade de possibilidades. A subjetividade dá possibilidades a partir do que se vê de oportunidades, quando se consegue identificar e ter consciência do que existe de possibilidades no mundo.

\section{LIMITES E POSSIBILIDADES NA VIDA DOS ADOLESCENTES- A IMPORTÂNCIA DE SE DESENVOLVER PROJETOS COM ADOLESCENTES (RESULTADOS E DISCUSSÕES)}

Os adolescentes a partir das vivencias que tiveram, passaram a ter consciência que existiam, por exemplo, Universidades e que para se chegar a determinado ponto, 
deveriam percorrer determinado caminho, e para percorrer é um preço que se paga, dentro da sua energia subjetiva. Quando se tem essa leitura e se sabe do que está acontecendo, temos aí uma apropriação de empoderamento, apropriação desse sujeito sobre sua própria vida.

Parar e pensar: O que vou gastar da minha vida com isso? Se dispor a estudar, por exemplo, é um preço caro, no qual gasta-se tempo, energia física, financeira e psicológica e outras coisas que se deve se sujeitar para ter no final a conclusão do objetivo. Não é algo fácil e esses adolescentes se conscientizaram do preço a pagar pelo investimento a partir das vivências.

A produção de subjetividade é ofertar aos adolescentes, não o acesso imediato a esses outros espaços (Instituições visitadas), mas produzir junto com eles essas novas possibilidades, esses novos caminhos de que antes eram inexistentes. Eles souberam desses espaços porque vivenciaram, não era um espaço que eles desconheciam teoricamente, pois faz parte do bairro em que residem, mas não sabiam como se apropriarem. A subjetividade se constitui a partir da existência/vivência.

Quando o indivíduo se encontra em uma situação adversa, é essencial que se estabeleça meta para sair de onde está, pois, a vida se apresenta em um caráter de missão, algo pelo qual precisamos alcançar, consciente e sempre com um objetivo. Essa motivação é a capacidade que cada indivíduo tem de reagir, buscar sentido e encontrar dentro de si o potencial, que é a autonomia de ser protagonista de sua história.

A psicologia compreende o ser humano em sua individualidade sem deixar de valorizar seu contexto biopsicossocial. O objeto por excelência da psicologia é o indivíduo, a sua subjetividade, não é possível, desse modo, a utilização somente da psicologia para o entendimento da subjetividade; são necessárias também as categorias da filosofia e da sociologia. Mesmo porque o sujeito, ao qual é associado o termo subjetividade, remete, simultaneamente, à universidade e à particularidade (CROCHIK, 1998).

Os adolescentes já têm conhecimento prévio de como se inserirem em uma instituição de ensino, curso técnico e como procurar um trabalho que não se resumisse somente em funções operacionais. Contudo, a disparada de novas possibilidades na vida dos adolescentes, deixa em aberto o que eles farão com esse investimento.

O texto procurou demonstrar que a prática do projeto direciona-se para um almejar além das perpectivas anteriores dos adolescentes. Fica como desafio saber quais foram os resultados das intervenções.

\section{CONSIDERAÇÕES FINAIS}


Cada personagem constrói sua história, juntos ou individualmente é gerado um movimento interno, um despertar para algo novo. O processo de protagonismo dos adolescentes no bairro que residem foi a ideia inicial, mas um projeto não deve se limitar, deve-se ser estendido o quanto for possível e necessário.

\section{REFERÊNCIAS}

BARUS-MICHEL, Jacqueline. O sujeito social. Belo Horizonte: Editora PUC Minas, 2004.

CARRETEIRO, Teresa Cristina. Cenários sociais e abordagem clínica. São Paulo: Editora Escuta, 2001.

CROCHIK, José Leon. Os desafios atuais do estudo da subjetividade na psicologia. Psicologia USP, v. 9, n 2, p. 69-85. 1998.

DELLAZZANA-ZANON, Letícia Lovato; DE LUCCA FREITAS, Lia Beatriz. Uma revisão de literatura sobre a definição de projeto de vida na adolescência. Interação em Psicologia, v. 19, n. 2, 2016.

MAYORGA, Claudia; PRADO, Marco Aurélio Máximo. Psicologia social: articulando saberes e fazeres. In: PSICOLOGIA SOCIAL: ARTICULANDO SABERES E FAZERES. Belo Horizonte, Editora Autêntica, 2007.

NETO, Fuad Kyrillos; OLIVEIRA, Rodrigo Torres; SILVA, Rogério de Oliveira; (Orgs.). Subjetividade(s) e sociedade: contribuições da Psicologia. Belo Horizonte: Conselho Regional de Psicologia de Minas Gerais, 2009.

RENA, Luiz Carlos C. B. (Coord.). Juventude em movimento: uma experiência de extensão universitária a partir do IV JUBRA. Organização: Letícia Soares de Souza, Rubens Ferreira do Nascimento, Vicente Almeida.Belo Horizonte: Ed. PUC Minas, 2012.

SANTOS, Victor Figueiredo; MARTINS, André Amorim. Protagonismo infanto juvenil no bairro belvedere: Nos limites da cidade. Diálogos e interaccriones de la Psicologia en América Latina. Buenos Aires. 2016. 